\title{
Impact of oxidative stress on male and female germ cells: implications for fertility
}

\author{
R John Aitken ${ }^{1,2}$ \\ ${ }^{1}$ Priority Research Centre in Reproductive Science, Faculty of Science and Faculty of Health and Medicine, \\ University of Newcastle, Newcastle, New South Wales, Australia and ${ }^{2}$ Hunter Medical Research Institute, University \\ of Newcastle, Newcastle, New South Wales, Australia
}

Correspondence should be addressed to R J Aitken; Email: john.aitken@newcastle.edu.au

\begin{abstract}
Male and female germ lines are vulnerable to oxidative stress. In spermatozoa, such stress triggers a lipid peroxidation cascade that culminates in the generation of electrophilic lipid aldehydes that bind to DNA and a raft of proteins involved in the delivery of functionally competent cells. One set of targets for these aldehydes are the proteins of the mitochondrial electron transport chain. When this interaction occurs, mitochondrial ROS generation is enhanced leading to the sustained generation of oxidative damage in a self-perpetuating cycle. Such damage affects all aspects of sperm function including motility, sperm-egg recognition, acrosomal exocytosis and sperm-oocyte fusion. Oxidative stress in the male germ line also attacks the integrity of sperm DNA with potential impacts on the developmental capacity of embryos and the health and wellbeing of the offspring. Potential pathways of reactive oxygen species (ROS) generation in male germ cells could involve enhanced lipoxygenase activity, activation of NADPH oxidase and/ or electron leakage from mitochondria. Similarly, in the female germ line, both the induction of oocyte senescence following ovulation and the deterioration of oocyte quality with maternal age appear to involve the generation of oxidative damage. In this case, the mitochondria appear to be a particularly important source of ROS compromising the viability and fertilizability of the oocyte and interfering with the normal segregation of chromosomes during meiosis. In light of these considerations, antioxidants should have some role to play in the preservation of reproductive function in both men and women; however, we still await appropriate trials to test this hypothesis.

Reproduction (2020) 159 R189-R201
\end{abstract}

\section{Introduction}

Redox reactions are an essential component of living systems and exist in a state of dynamic equilibrium whereby the loss (oxidation) and gain (reduction) of electrons are carefully balanced. Oxidative stress is created when the generation of reactive oxygen species (ROS) by a given cell, tissue or fluid exceeds the protective capacity of the intrinsic antioxidant mechanisms. ROS, in this context, refers to any molecule or compound capable of oxidizing biological substrates including fats, proteins and DNA and may come in the form of free radicals characterized by unpaired valency electrons (such as superoxide anion $\left[\mathrm{O}_{2}^{--}\right]$generated by the one electron reduction of molecular oxygen) or powerful oxidants (such as hydrogen peroxide $\left[\mathrm{H}_{2} \mathrm{O}_{2}\right]$ or peroxynitrite $\left[\mathrm{ONOO}^{-}\right]$). Antioxidants, on the other hand, come in the form of enzymes that metabolize potentially toxic ROS such as hydrogen peroxide (the glutathione peroxidase system or catalase) and $\mathrm{O}_{2}{ }^{-}$ (e.g. superoxide dismutase or, possibly, indoleamine dioxygenase) or small molecular mass scavengers that can terminate free radical-mediated chain reactions (such as vitamins C and E or a variety of polyphenols). Some proteins (e.g. lactoferrin) or small molecules (e.g. penicillamine) can also provide antioxidant protection by chelating transition metals that, by redox cycling, can catalyse free radical-mediated reactions.

These pro- and anti-oxidant systems normally exist in a state of balance whereby biologically important oxidation reactions are allowed to occur in a carefully controlled manner. However, if this balance is perturbed because of a lack of antioxidant protection or an overproduction of ROS, then a state of imbalance is created and substrates become oxidized in a unregulated manner leading to pathological change. Some of the products created by such random acts of oxidative vandalism may also be cytotoxic and exacerbate the state of stress. For example, electrophilic lipid aldehydes (such as 4-hydroxynonenal [4HNE] or acrolein) generated as a consequence of lipid peroxidation can themselves bind to a wide variety of biologically important targets, such as the nucleophilic centres of proteins and modify the function of these molecules in a way that powerfully reinforces the pathological impact. For example, lipid 
aldehydes can bind to proteins in the mitochondrial electron transport chain including ATP synthase subunit $\beta$ (ATP5B), succinate dehydrogenase [ubiquinone] flavoprotein subunit (SDHA) and NADH dehydrogenase [ubiquinone] iron-sulfur protein 2 (NDUFS2) (Zong \& Yin 2015). As a result of this interaction the electron transport process becomes disorganised, leading to the leakage of electrons that are immediately swept up by the universal electron acceptor, oxygen, to generate $\mathrm{O}_{2}^{-}$; the latter then rapidly dismutates to hydrogen peroxide, which promotes further lipid peroxidation thereby propagating the state of oxidative stress (Aitken et al. 2012). Such mechanisms are capable of creating oxidative damage in a variety of biological systems and are thought to underpin a wide range of pathologies including Parkinson's disease, cancer, artherosclerosis, heart failure, Alzheimer's, depression and ageing. However, there are few systems as vulnerable to oxidative attack as the reproductive system.

Oxidative stress has been repeatedly implicated in the aetiology of male infertility (Bisht et al. 2017, Aitken 2018), including the reproductive toxicity that flows from exposure to environmental toxicants (Kovacic \& Jacintho 2001) and electromagnetic radiation (Houston et al. 2016) as well as clinical conditions such as varicocoele (Agarwal et al. 2009) and testicular torsion (Vaos \& Zavras 2017). Oxidative stress has also been implicated in the aetiology of female infertility, including such conditions as polycystic ovary syndrome, endometriosis, premature ovarian failure and preeclampsia (Lu et al. 2018, Park et al. 2018). In addition, oxidative stress has been linked with the negative impact of repeated ovarian stimulation on reproductive competence (Chao et al. 2005) as well as the developmental potential of oocytes in an IVF setting (Das et al. 2006) or in response to ageing (Lord \& Aitken 2013, Mihalas et al. 2017). Following the establishment of pregnancy, this form of stress can again impact the functionality of the placenta and ultimately the health and wellbeing of the foetus, with implications for the aetiology of miscarriage, premature rupture of the membranes and foetal death (Burton \& Jauniaux 2011, Maiti et al. 2017, Domínguez-Perles et al. 2019).

A detailed consideration of the role of oxidative stress in the causation of reproductive disorders is of importance because it has clear implications for the prevention, diagnosis and therapeutic resolution of such conditions. In this review, we shall consider evidence supporting a role for oxidative stress in the pathophysiology of reproductive disease with particular emphasis on the male and female germ line.

\section{Oxidative stress in the male}

\section{Precursor germ cells}

One of the first reproductive functions shown to be vulnerable to oxidative stress was male fertility. We have known that the male germ line is vulnerable to oxidative stress since the sterilizing impact of ionizing irradiation on male fertility was discovered in the 1930s (Snell \& Aebersold 1937, Ogilvy-Stuart \& Shalet 1993). The differential sensitivity of testicular germ cells to the free radicals generated by ionizing radiation is also indicated by the powerful protective action of antioxidants such as melatonin (Hussein et al. 2006) and has been exploited in the extensive use of radiation therapy to successfully treat testicular germ cell tumours (Rajpert-De Meyts et al. 2016). The vulnerability of precursor germ cells to oxidative stress is also reflected in the reproductive consequences of testicular heating. Thus, for the testes to be fully functional, they have to operate at a degree or two lower than core body temperature. Heating the testes to $40-41^{\circ} \mathrm{C}$ induces a rapid loss of germ cells at the pachytene spermatocyte and spermatid stages of differentiation via a combination of Fas-mediated apoptosis and autophagy (Zhang et al. 2012). The loss of fertility observed under these circumstances can be completely reversed by the direct administration of antioxidants or treatments that elevate the levels of antioxidant protection within the testes (Gharagozloo et al. 2016, Kumar Roy et al. 2016). The role of oxidative stress in mediating the effects of testicular heating has also been indicated in studies involving male germ cells from SOD-1-knockout mice which were shown to be more vulnerable to heat stress than controls, in vitro and in vivo (Ishli et al. 2005). Testicular germ cells are thus vulnerable to oxidative stress and none more so than round spermatids, which are particularly vulnerable to lipid peroxidation and the cytotoxic consequences of lipid aldehyde generation (Bromfield et al. 2017). It has been proposed that this particular stage of germ cell development is vulnerable to a form of cell death known as ferroptosis, which is dependent on iron and driven by the peroxidative degradation of lipids and accumulation of electrophilic aldehydes such as 4-HNE (Bromfield et al. 2019). Furthermore, oxidative stress at the spermatid stage is thought to underpin the subsequent appearance of functional defects in the spermatozoa particularly their competence for sperm-egg recognition (Bromfield et al. 2017).

\section{Spermatozoa}

The central role of oxidative stress in regulating the functionality of spermatozoa has been recognized since the pioneering studies of Tosic and Walton on the susceptibility of bovine spermatozoa to hydrogen peroxide (Tosic \& Walton 1946, 1950). John MacLeod similarly observed the susceptibility of human spermatozoa to hydrogen peroxide stress following the incubation of these cells for prolonged periods of time in high oxygen-tension media (MacLeod 1943). Indeed, spermatozoa were the first cell type in which the metabolic generation of cytotoxic quantities of hydrogen 
peroxide was indicated, preceding the discovery of ROS generation by phagocytic leukocytes by several decades (McLeod 1943, Babior et al. 1973). The protective effect of catalase on sperm motility, demonstrated initially by McLeod (1943) and substantiated by Aitken et al. (1993), strongly suggests that the primary cytotoxic ROS is hydrogen peroxide generated by the dismutation of $\mathrm{O}_{2}^{-\cdot}$ (Alvarez et al. 1987). These observations raise fundamental questions about the sources of ROS driving male infertility as well as their mechanisms of action, functional significance and potential remediation.

\section{Sources of ROS in sperm - amino acid oxidase}

The biochemical sources of the ROS generated by mammalian spermatozoa have still not been fully resolved but are clearly multiple (Aitken et al. 2003) and vary significantly between species (Fig. 1). The first source to be identified was an amino acid oxidase in bovine spermatozoa (Tosic \& Walton, 1950). This oxidase utilizes aromatic amino acids as substrate (tyrosine, tryptophan and phenylalanine) and generates hydrogen peroxide and ammonia in the presence of oxygen. An interesting feature of this system is that its contribution to the redox status of bovine sperm was insignificant until the spermatozoa were immersed in an egg-yolkbased extender, in preparation for cryostorage. At this moment, the free aromatic amino acids present in egg yolk stimulated such high levels of ROS generation that motility was curtailed. It was subsequently demonstrated that the simple addition of isolated aromatic amino acids, such as phenylalanine or tyrosine, to suspensions of bovine spermatozoa was enough to suppress their motility and, ultimately, their vitality (Lapointe \& Sirard 1998). Interestingly the source of the ROS was traced to the dead cells in the ejaculate which, because of

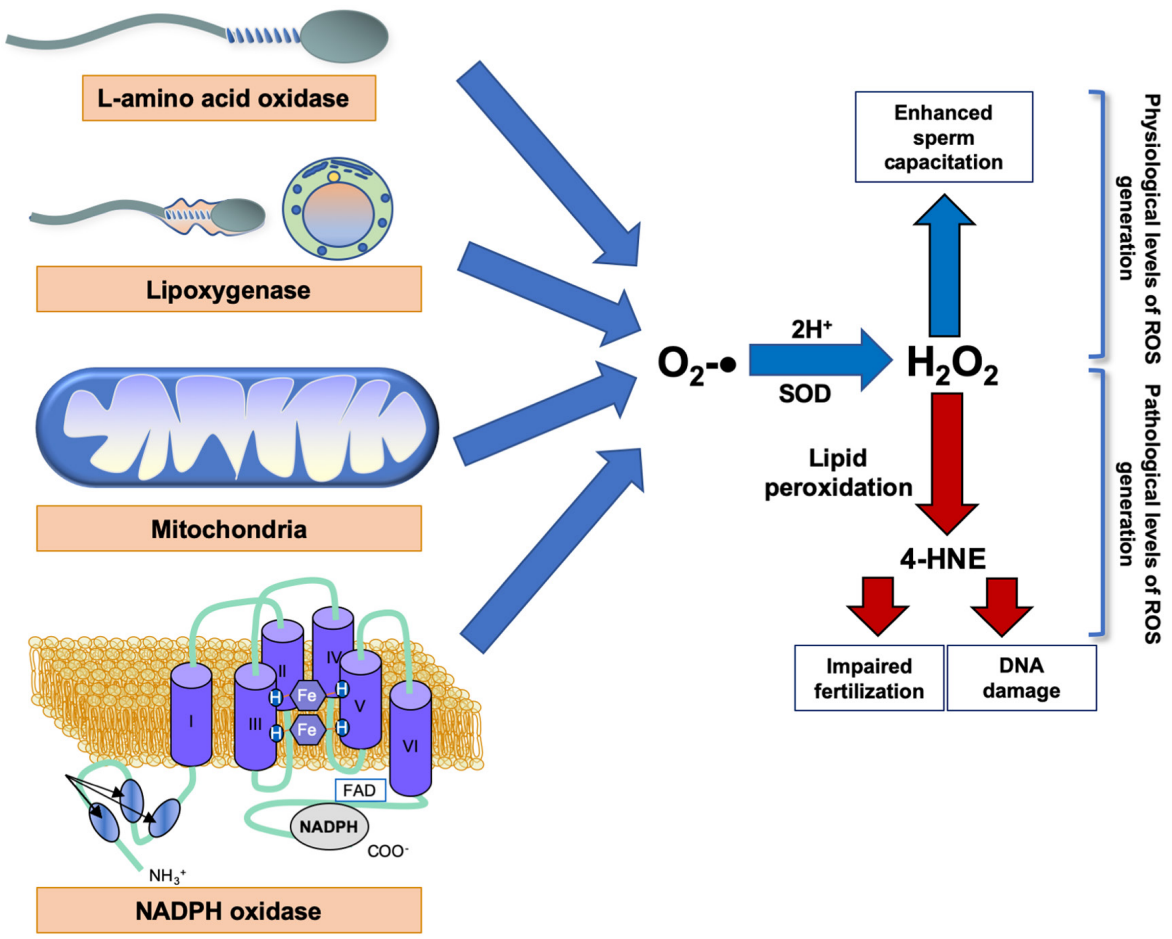

Figure 1 Possible mechanisms by which oxidative stress can be created in spermatozoa. The spermatozoa of several species are known to possess an L-amino oxidase that uses aromatic amino acids as substrate (Houston et al. 2015). The biological purpose of these oxidases is not known with certainty; however, they are a significant source of damaging ROS in domestic animals (bull, stallion and ram) exposed to high concentrations of aromatic amino acids in egg yolk-based cryopreservation media. Lipoxygenase is another potential source of ROS, the presence of which may reflect the retention of excess residual cytoplasm as a consequence of defective spermiogenesis and the presence of excess free unesterified free fatty acids (Walters et al. 2018). Lipoxygenase may also be a source of ROS in round spermatids by triggering a caspase-independent form of apoptosis known as ferroptosis (Bromfield et al. 2019). The mitochondria are a major source of ROS in spermatozoa and are heavily involved in the induction of senescence and apoptosis (Koppers et al. 2011). Many species, not mouse, also possess an NADPH oxidase (NOX5) that is capable of generating ROS in a calcium-dependent manner. Overexpression of this enzyme has been linked to the loss of sperm motility observed in asthenozoospermia (Vatannejad et al. 2019). The major product from all of these sources is $\mathrm{O}_{2}{ }^{-}$. which then dismutates to $\mathrm{H}_{2} \mathrm{O}_{2}$ under the influence of superoxide dismutase (SOD). $\mathrm{H}_{2} \mathrm{O}_{2}$ is a powerful membrane permeant oxidant that when generated in moderate amounts stimulates sperm capacitation. However, in excess, this oxidant attacks unsaturated fatty acids in the plasma and mitochondrial membranes to induce a lipid peroxidation cascade culminating in the genesis of small molecular mass electrophilic aldehydes such as 4-HNE. The latter then binds to nucleophilic centres within DNA and proteins, inducing a range of pathological challenges to the functionality of spermatozoa and the integrity of their genetic cargo. 
their ruptured plasma membranes, were able access the amino acid substrates that fuel the oxidase's ROSgenerating activities. In light of these results, the semen extenders used for bovine sperm cryostorage have been reconfigured to contain catalase, to scavenge the hydrogen peroxide emanating from dead spermatozoa in the ejaculate before the motility and vitality of the live cells could become compromised (Shannon \& Curson 1982). Similarly, in ram and equine spermatozoa an aromatic amino acid oxidase has been found with similar attributes to the bovine enzyme. Thus, non-viable ram and equine spermatozoa respond to exogenous aromatic amino acids such as L-phenylalanine with a significant increase in ROS generation that then suppresses the total and progressive motility in the live sperm population (Upreti et al. 1998, Aitken et al. 2015a). Importantly the D-forms of these amino acids are incapable of stimulating ROS generation by mammalian spermatozoa; only the $\mathrm{L}$-amino acids are active in this system.

Human spermatozoa also possess an amino acid oxidase with a preference for aromatic amino acids particularly phenylalanine and tryptophan. The L-amino oxidase enzyme in human spermatozoa is encoded by interleukin (IL)-4-induced gene1 (IL4I1), and the gene product is located in the head and midpiece of the cell (Houston et al. 2015). In contrast to other species, the enzyme is not retained by dead cells that have lost integrity in their plasma membranes. As a result, non-viable spermatozoa do not respond to aromatic amino acid stimulation and so the threat posed by cryopreservation media supplemented with egg yolk does not apply in the case of human spermatozoa (Houston et al. 2015).

The functional significance of this amino acid oxidase is the subject of ongoing discussion but might be related to the induction of sperm capacitation. This process is known to be redox regulated, driven by the ability of ROS to effect a number of critical changes in these cells, including cholesterol oxidation, activation of cAMP generation and inhibition of tyrosine phosphatase activity (Aitken \& Curry 2011, Brouwers et al. 2011). Exposure to exogenous phenylalanine will induce such changes via mechanisms that can be reversed by the concomitant presence of catalase, suggesting that hydrogen peroxide is the active ROS in this instance, as suggested by others (Bize et al. 1991, Rivlin et al. 2004). In keeping with this hypothesis, exogenous phenylalanine does induce capacitation and the acrosome reaction in human spermatozoa (Houston et al. 2015). However, the quantities of phenylalanine required to achieve this effect $(5-10 \mathrm{mM})$ are higher than the physiological concentrations of phenylalanine in human or, even, bovine uterine fluid (Elhassan et al. 2001, Kermack et al. 2015). Alternative functions for this oxidase include the oxidative deamination of aromatic amino acids, generating keto acids that are then oxidized by the sperm mitochondria. Such a role may be particularly important in stallion spermatozoa which are highly dependent on oxidative phosphorylation to meet their energy needs and relatively resistant to oxidative stress (Griffin et al. 2019). This rationale may also apply to the spermatozoa of other ungulates such as the boar and bull (Storey 2008) which are also heavy users of oxidative phosphorylation. However, this explanation does not apply to human spermatozoa which are primarily driven by glycolysis (Calvert et al. 2019). Yet another possibility is that the human oxidase, IL4I1, may be part of an ancient bactericidal system, as a consequence of the generation of ammonia and hydrogen peroxide. IL4I1 may also limit T-lymphocyte activation and proliferation, in part, via the production of hydrogen peroxide and local phenylalanine depletion. The diminished T cell activation would, in turn, lead to impaired proliferation and a disrupted capacity to produce Th1 cytokines and proinflammatory chemokines, creating a state of immunotolerance towards these potentially immunogenic cells (Castellano \& Molinier-Frenkel 2017).

\section{Sources of ROS in sperm - mitochondria}

Another potential source of ROS, particularly in moribund or senescent spermatozoa, are the mitochondria (Koppers et al. 2008; Fig. 1). Human spermatozoa are unusual in that while they may possess mitochondria in the midpiece, they normally rely heavily on the oxidation of substrates via the glycolytic pathway to meet their energy demands. Moreover, human sperm mitochondria are highly prone to electron leakage, leading to ROS generation and the suppression of sperm function. A variety of factors are known to promote ROS generation by human sperm mitochondria, some directly, by interfering with the regulated passage of electrons along the electron transport chain, such as radiofrequency electromagnetic radiation (Houston et al. 2018) or polyunsaturated fatty acids (Aitken et al. 2006) and others indirectly by triggering the intrinsic apoptotic pathway, such as parabens or bisphenol A (Barbonetti et al. 2016, Samarasinghe et al. 2018).

The unregulated leakage of electrons from human sperm mitochondria is capable of causing extensive oxidative harm to these cells including the induction of significant DNA damage, lipid peroxidation and motility loss (Houston et al. 2018). Clinically, the excessive generation of ROS by human sperm mitochondria has been linked to defective sperm function including the loss of motility seen in asthenozoospermia patients (Cassina et al. 2015, Nowicka-Bauer et al. 2018). In principle, electron leakage can occur at either Complex 1 or Complex III, although the former seems to be the most damaging. This is because ROS generation at Complex III leads to the rapid release of hydrogen peroxide into the extracellular space, whereas ROS produced at Complex I are released to the matrix where they can induce peroxidative damage to the inner mitochondrial membrane (Koppers et al. 2008). 
Although the enhanced mitochondrial ROS generation, seen spontaneously in the defective spermatozoa of infertile patients or triggered by cytotoxic reagents, has been linked with a loss of mitochondrial membrane potential (MMP) (Wang et al. 2003), this association may be indirect in nature. Thus, it has been found that electron transport inhibitors can readily stimulate mitochondrial ROS generation in human spermatozoa in the absence of any immediate change in MMP (Koppers et al. 2008). However, it is very possible that the prolonged generation of ROS from Complex 1 in the immediate vicinity of the inner mitochondrial membrane might secondarily lead to an opening of the transient permeability transition pore and a secondary collapse of the MMP (Zorov et al. 2014).

\section{Sources of ROS in sperm - NADPH oxidase and sperm capacitation}

The possible involvement of an NADPH oxidase in the generation of ROS by human spermatozoa was suggested by the discovery that the addition of this co-enzyme to suspensions of human spermatozoa could induce a burst of oxidative activity reflected by an increase in lucigenin-dependent chemiluminescence (Aitken et al. 1997; Fig. 1). Although reservations have been rightly raised about the specificity of the lucigenin probe as a means of detecting $\mathrm{O}_{2}^{--}$(Baker et al. 2004, 2005), the same burst of activity was observed when acetylated cytochrome $\mathrm{C}$ reduction, a more specific $\mathrm{O}_{2}{ }^{-\cdot}$-detection reagent, was used to monitor the response to NADPH (Aitken et al. 1997). Furthermore, the involvement of an NADPH oxidase in the generation of ROS by human spermatozoa has been suggested by the suppressive action of diphenylene iodonium (DPI), a recognized NADPH oxidase inhibitor (Aitken et al. 1997). Although DPI is a generalized flavoprotein inhibitor, which is necessarily not specific for NADPH oxidase activity, Donà et al. (2011) demonstrated that ROS production by human sperm suspensions could be suppressed by another NADPH oxidase inhibitor, apocynin. Moreover, the generation of ROS by purified suspensions of human spermatozoa was shown to be correlated with intracellular glucose-6-phosphate dehydrogenase, a key determinant of intrinsic intracellular NADPH generation via the hexose monophosphate shunt (Aitken et al. 1994). Finally, an NADPH oxidase (NOX5) has been definitively identified in human spermatozoa and shown to generate ROS in a calcium-dependent manner via mechanisms involving the mediation of a non-receptor tyrosine kinase, c-Abl, and the HV1 proton channel (Musset et al. 2012).

The NCBI gene database indicates that the gene encoding the NOX5 protein is present in the genome of several mammalian species including cattle, horse, pig, cat, dog, rabbit, chimpanzee, rhesus monkey, armadillo, ferret, opossum and human. However the NOX5 gene does not appear to be represented in the mouse genome. So if NOX 5 does, as proposed, play a central role in sperm biology, it is not a ubiquitous mechanism. Nevertheless, from a clinical perspective, asthenozoospermia has been associated with the over-expression of NOX5 compared with normozoospermic males, as well as significantly elevated levels of peroxynitrite, $\mathrm{O}_{2}{ }^{-\cdot}$ and hydrogen peroxide generation (Vignini et al. 2006, Vatannejad et al. 2019). In view of these data, a potential role for this oxidase in the pathogenesis of defective sperm function cannot be ruled out.

\section{Polyunsaturated fats and lipoxygenase}

Another source of ROS within the male germ line is lipoxygenase (Fig. 1). It has been known for some time that polyunsaturated fatty acids can induce ROS formation by human spermatozoa (Aitken et al. 2006). In addition to arachidonic acid, this activity could be induced by other cis-unsaturated fatty acids including linoleic and docosahexaenoic acids; however, saturated fatty acids, methyl esters of unsaturated fatty acids or other amphiphiles were all ineffective. The relevance of these findings to male infertility was suggested by the positive correlation that has been observed between the free unsaturated fatty acid content of defective human spermatozoa and their relative capacity for spontaneous mitochondrial $\mathrm{O}_{2}^{--}$generation (Koppers et al. 2010). The underlying mechanism was postulated to be the disruption of regulated electron flux along the mitochondrial electron transport chain, leading to the leakage of electrons that are then swept up by oxygen to generate $\mathrm{O}_{2}^{--}$. Another possibility is that polyunsaturated fatty acids somehow promote the opening of the mitochondrial permeability transition pore (mPTP) which, in turn, leads to a loss of mitochondrial membrane potential, followed by electron leakage and $\mathrm{O}_{2}^{--}$generation in spermatozoa. The link between polyunsaturated fats such as arachidonic acid and mPTP opening could involve the mediation of hydroxyeicosatetraenoic acids (HETEs) generated via lipoxygenase action. HETEs are known to activate $\mathrm{Ca}^{2+}$-induced opening of the MPTP in, for example, the failing heart, and exposure to lipoxygenase inhibitors has been found to attenuate this process (Moon et al. 2018). Under normal circumstances, the unsaturated fat that dominates the sperm lipid profile, decosahexaenoic acid, might be expected to suppress mPTP opening (Khairallah et al. 2010). However, in the presence of excess lipoxygenase, unsaturated fatty acids, particularly arachidonic acid, would be expected to stimulate HETE generation, mPTP opening, electron leakage and ROS generation in a chain of cause and effect. Normally, most lipoxygenase activity is lost from mammalian spermatozoa during epididymal maturation when the cytoplasmic droplet is discarded (Fischer et al. 2005). However, defective human spermatozoa have been shown to possess excess residual cytoplasm (Gomez 
et al. 1996) and, as a consequence, are associated with an elevated cellular content of lipoxygenase activity as well as excess arachidonate (Yu et al. 2019). Moreover, suppression of lipoxygenase activity in human spermatozoa has been shown to protect human spermatozoa from the oxidative stress, created following exposure to exogenous hydrogen peroxide (Walters et al. 2018). A possible interpretation of these data would be that (1.) hydrogen peroxide exposure directly induces lipid peroxidation; (2.) major by-products of the lipid peroxidation cascade include lipid aldehydes that bind to redox centres within the mitochondrial electron transport chain stimulating the regeneration of sustained high levels of ROS; (3.) sustained oxidative stress leads to mitochondrial calcium overload; (4.) elevated intra-mitochondrial calcium levels then lead to the stimulation of PLA2 activity which induces an increase in free arachidonate and lipoxygenase-mediated HETE generation and (5.) the HETEs promote mPTP opening, a consequential collapse of mitochondrial membrane potential, ATP depletion, yet more ROS generation and finally induction of the intrinsic apoptotic cascade and creation of DNA damage (de Lamirande \& Gagnon 1992, Peng \& Jou 2010, Koppers et al. 2011). Such a cascade is consistent with the clear linkages that have been reported on many independent occasions between impaired sperm function and elevated mitochondrial ROS generation, lipid peroxidation, intracellular calcium overload, mPTP opening, loss of mitochondrial membrane potential and DNA damage (Aitken \& Curry 2011, Zhang et al. 2014). Clearly, further studies will have to be conducted to determine the details of how all of these various factors intersect.

\section{Redox regulation of sperm function - the yin and the yang}

Whilst it is becoming clear that excess ROS generation by spermatozoa is involved in the aetiology of defective sperm function, this leaves open the question as to why spermatozoa would evolve systems for the generation of ROS in the first place; particularly when the vulnerability of these cells to oxidative stress is so apparent. The answer to this question appears to be that a key aspect of sperm physiology, namely their ability to capacitate, is redox regulated.

In this context, it has been repeatedly shown that capacitation has been linked to the cellular generation of ROS (Bize et al. 1991, de Lamirande \& Gagnon 1993, Rivlin et al. 2004, Aitken et al. 2015b) which is, in turn, dependent on the presence of bicarbonate and cytoplasmic alkalinization (Ecroyd et al. 2003). Furthermore, the ROS-generating capacity of spermatozoa can be reduced by DPI, high concentrations of $\mathrm{Zn}$ and semenogelin, all of which suppress sperm capacitation (Ecroyd et al. 2003, de Lamirande \& Lamothe 2010). Conversely, the Zn chelator, TPEN, enhances $\mathrm{O}_{2}{ }^{--}$anion generation and stimulates sperm capacitation (de Lamirande et al. 2009). Progesterone, a physiological promoter of sperm capacitation and acrosomal exocytosis, has also been found to stimulate ROS generation (Ghanbari et al. 2019). Moreover, ROS generation stimulates cAMP generation, cholesterol oxidation and tyrosine phosphorylation, all of which are associated with the attainment of a capacitated state (White \& Aitken 1989, Aitken et al. 1998b, Lewis \& Aitken 2001, Aitken \& Nixon 2013).

An additional contribution to the physiological induction of sperm capacitation may also be made by another radical species, nitric oxide (NO), which can induce many of the hallmarks of sperm capacitation including an upregulation in phosphotyrosine expression, the stimulation of hyperactivated movement and the enhancement of sperm-zona interaction (Zini et al. 1995, Sengoku et al. 1998, Herrero et al. 1999). Furthermore, a lack of NO stimulation appears to be associated with sperm pathologies of various kinds (Kalezic et al. 2018). Just as we saw with $\mathrm{O}_{2}^{-}, \mathrm{Zn}$ inhibitors and $\mathrm{Zn}$ chelators promote both $\mathrm{NO}$ generation by human spermatozoa and capacitation (de Lamirande et al. 2009). Moreover, seminogelin, the major protein constituent of the human semen coagulum, blocks capacitation via the suppression of both $\mathrm{O}_{2}^{--}$and $\mathrm{NO}$ generation (de Lamirande \& Lamothe 2010). Exposure of human spermatozoa to NO sources has also been shown to promote the tyrosine phosphorylation events associated with capacitation, while nitric oxide synthase inhibitors have been found to suppress this process (Herrero et al. 1999). The rapid reaction between $\mathrm{NO}$ and $\mathrm{O}_{2}{ }^{-*}$ anion creates the powerful oxidant, peroxynitrite $\left(\mathrm{ONOO}^{-}\right)$. Peroxynitrite modifies tyrosine in proteins to create nitrotyrosines, leaving a detectable footprint. Human spermatozoa have been shown to express nitrotyrosine residues suggesting that peroxynitrite, a strong oxidizing agent, may well be a physiological inducer of the oxidative changes associated with sperm capacitation in vivo, including both hyperactivation and the sperm-zona binding competence of these cells (Herrero et al. 2001). The generation of such a powerful oxidant during sperm capacitation will also inevitably place limits on the longterm survival of spermatozoa once they have engaged the capacitation process. Indeed, following this line of logic, it has been suggested that sperm capacitation and senescence are opposite ends of a biological continuum driven by peroxynitrite (Aitken et al. 2015b).

In light of the foregoing, it is clear that reactive oxygen and nitrogen species are two-edged swords as far as spermatozoa are concerned. On the one hand, these reactive metabolites are critical to the cascade of oxidative events driving sperm capacitation by virtue of their capacity to stimulate cAMP generation, impair tyrosine phosphatase activity and enhance oxysterol formation. On the other, over-capacitation of spermatozoa leads to a state of senescence and the activation of a truncated 
intrinsic apoptotic cascade characterized by enhanced mitochondrial ROS generation, lipid oxidation, motility loss, caspase activation and phosphatidylserine externalization (Aitken et al. 2015b). This truncated apoptotic cascade constitutes a regulated biological mechanism that allows spermatozoa that are surplus to requirements to die in a carefully controlled manner. This is important because it permits the immune system to phagocytose senescent spermatozoa without triggering an unwanted inflammatory response. This situation arises by virtue of the fact that apoptotic cells, expressing phosphatidylserine on their surface, are able to induce a 'silent' phagocytosis on behalf of the neutrophils and macrophages entering the lower female reproductive tract following insemination (Aitken \& Baker 2013). Levels of oxidative stress that are not sufficient to induce cell death via apoptosis are still capable of disrupting all aspects of sperm function including motility, spermzona recognition, acrosomal exocytosis and spermoocyte fusion. In addition, sublethal levels of oxidative stress are known to impact the integrity of sperm DNA thereby influencing the potential development of the embryo and the health and wellbeing of the offspring (Aitken et al. 1998a, Aitken \& Curry 2011, Aitken 2018). For example, the altered patterns of gene expression observed in equine embryos as a consequence of insemination with cryostored spermatozoa maybe a case in point, because cryostorage is known to be associated with the induction of oxidative DNA damage (Thomson et al. 2009, Ortiz-Rodriguez et al. 2019).

\section{Oxidative stress in the female}

\section{The oocyte}

The female germ line is as vulnerable to oxidative stress as the male. Just as oxidative stress plays a key role in the senescence of spermatozoa post ejaculation, such stress appears to be central to the mechanisms by which the oocyte loses its developmental competence post ovulation. In this context, oocytes are actually more vulnerable than spermatozoa. Within a few hours of ovulation, the oocyte loses its viability and functionality, while ejaculated spermatozoa are designed to spend several days in the female reproductive tract waiting for an egg to arrive; particularly in our own species where the acts of insemination and ovulation are not synchronized by the expression of oestrus. Oocytes are therefore programmed to die rapidly after ovulation unless they are rescued by union with a spermatozoon - whereupon they become (potentially) immortalized.

The mechanism by which postovulatory oocytes enter apoptosis and lose their functionality involves a complex series of events, all of which are driven by an increase in oxidative stress. For example, zona pellucida hardening is a classic feature of post-ovulatory oocyte ageing which can be driven by exposure to $\mathrm{O}_{2}^{--}$and involves the cross linking of tyrosine residues. This oxidative event is catalysed by an ovoperoxidase located in cortical granules which are released from the oocyte surface in an exocytotic process which is facilitated by ageing and is, again, driven by $\mathrm{O}_{2}^{-\cdot}$ (Hoodbhoy \& Talbot 1994, Goud et al. 2008). Oxidative stress also appears to be involved in the non-dysjunction of chromosomes that characterizes oocytes that have aged in vivo and is responsible for the exponential increase in aneuploidy in the embryos conceived by woman over the age of 35 (Tarin et al. 1998).

In a manner reminiscent of senescent spermatozoa, oxidative stress during the post-ovulatory ageing of oocytes is created by the leakage of electrons from the oocyte mitochondria driving a lipid peroxidation process that culminates in the generation of toxic lipid aldehydes such as 4-HNE and acrolein (Lord et al. 2015, Jeelani et al. 2018). These aldehydes, in turn, mediate a great deal of the cellular damage that ultimately induces the post-ovulatory apoptotic demise of the oocyte including the induction of mitochondrial ROS generation, a loss of mitochondrial membrane potential, DNA damage and activation of the intrinsic apoptotic cascade. A major target for these electrophilic aldehydes again appears to be proteins within the mitochondrial electron transport chain such as succinic acid dehydrogenase. Adduction of this enzyme by lipid aldehydes such as acrolein or 4-HNE disrupts electron flow within the mitochondria, promoting electron leakage and ROS generation, that then reinforce the creation of oxidative stress in a positive feedback loop. As a result of this chemistry, the oxidative attack becomes sustained, initiating a cascade of events that create the aged-oocyte phenotype (Lord \& Aitken 2013).

Remarkably, the act of fertilization abruptly halts this self-induced, post-ovulatory decline in viability; however, how this is achieved is currently unknown. We do know that fertilization is followed by a sudden increase in the DNA-repair capacity of the oocyte such that the latter is significantly more resistant to the ability of etoposide to elicit double strand breaks in oocyte DNA. This change is at least partly mediated by the fertilizationdependent upregulation of permeability glycoprotein (PGP), an endogenous multidrug efflux transporter that is translocated to the oolemma and phosphorylated upon oocyte activation, thereby enhancing the ability of the oocyte to remove compounds that might compromise DNA integrity (Martin et al. 2016). Many other changes are invoked in the oocyte following fertilization, not least the activation of calcium oscillations by spermspecific phospholipase C. These transients are clearly critical for arresting the tendency of oocytes to descend into an apoptotic decline while activating embryonic development (Swann \& Lai 2016). However, the precise mechanism by which these calcium oscillations so dramatically alter the downward, developmental trajectory of the oocyte have not yet been resolved. 
Similar oxidative processes appear to mediate the impact of chronological age on oocyte function. In this context, oocytes recovered from ageing female mice are characterized by significantly elevated levels of ROS generation and lipid aldehyde formation as well as a high tendency for chromosome non-dysjunction (Lord et al. 2015, Mihalas et al. 2017). One of the targets for these electrophilic aldehydes appears to be the proteins involved in the control of chromosome segregation during meiosis (Mihalas et al. 2017). Significantly, the agedependent increase of chromosomal non-dysjunction seen in Drosophila oocytes can be completely reversed by the engineered overexpression of SOD 1 and SOD 2 during meiotic prophase. Such studies support the notion that the exponential increase in oocyte aneuploidies seen in ageing women is related to an age-induced increase in oxidative stress that might be amenable to correction through the judicious administration of exogeneous antioxidants (Perkins et al. 2019).

An interesting question which is yet to be addressed is whether there are other sources of ROS generation in oocytes. These cells are apparently rich in NADPH oxidase enzymes (Maru et al. 2005) and, in some species at least, strong lipoxygenase activity has been detected in the oocyte, with a potential role in oocyte maturation (Hawkins \& Brash 1987). However, the contribution of such systems in the biology and pathology of the oocyte is currently unknown (Fig. 2).

\section{Antioxidants}

In light of the important role that oxidative stress plays in the aetiology of defective sperm and oocyte function, it is possible that antioxidants may have a therapeutic role to play in the context of both in vitro fertilization outcomes and in controlling the impact of age on fertility. In vitro, a variety of antioxidants have been shown to enhance the fertilizability of oocytes following in vitro maturation. For example, the presence of sodium selenite in the medium has been shown to significantly increase the vitro maturation of mouse oocytes while suppressing the generation of ROS and increasing mtDNA copy number (Ghorbanmehr et al. 2018), presumably through the stimulation of glutathione peroxidase activity (a key antioxidant enzyme with selenium in its active site). Positive impacts on the in vitro maturation of mammalian oocytes have also been recorded for $\alpha$-tocopherol, either alone (Arias-Álvarez et al. 2018) or mixed with additional antioxidants (alpha-lipoic acid, hypotaurine and $\mathrm{N}$-acetyl cysteine) (Pasquariello et al. 2019), 9-cis-retinoic acid (Gad et al. 2018), coenzyme Q10 (Heydarnejad et al. 2019) melatonin (An et al. 2019), rosmarinic acid (Zhang et al. 2019) and the antioxidant citrus flavonoid, hesperetin (Kim et al. 2019). Antioxidants have also been shown to ameliorate the oxidative stress associated with oocyte vitrification (Trapphoff et al. 2016, Wang et al. 2018, Ahmadi et al. 2019) repeated superovulation (Xiao et al. 2019), induced polycystic ovarian disease (Eini et al. 2019) post-ovulatory oocyte ageing (Liang et al. 2018), exposure to heat stress (Cavallari et al. 2019), old age (Liu et al. 2013) or a variety of toxicants in vitro such as menadione, bisphenol A (Cavallari et al. 2019, Li \& Zhao 2019), Fenoxaprop-ethyl (He et al. 2019) and busulfan/ cyclophosphamide chemotherapeutic combinations (Wu et al. 2019).

Oxidative stress has also been suggested as a detrimental factor in the determination of ICSI success

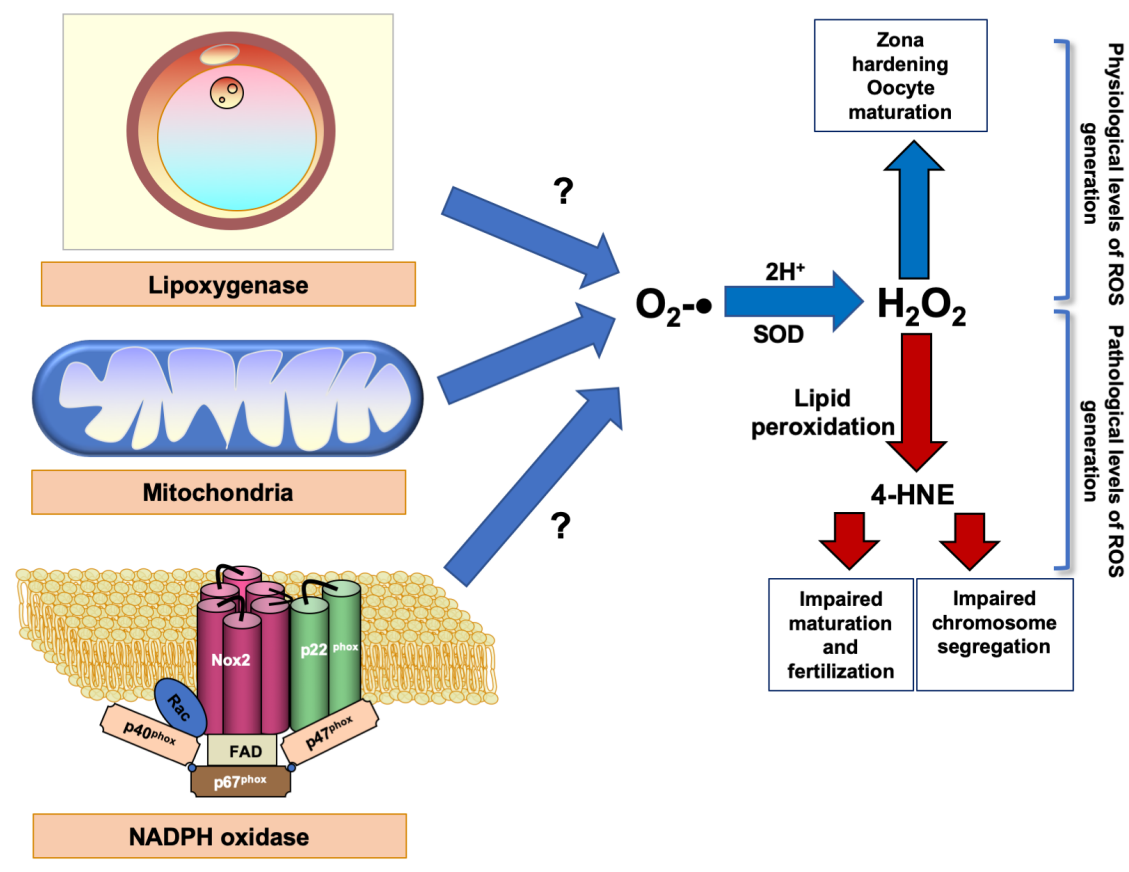

Figure 2 Sources of ROS in oocytes. Much less is known about ROS generation in oocytes. Post-ovulatory oocyte ageing clearly involves ROS generation by the mitochondria (Lord \& Aitken 2013). While oocytes possess NADPH oxidase (NOX2) and lipoxygenase, the role of these pathways in creating oxidative stress within the female germ line is unknown. Whatever the origins of the $\mathrm{O}_{2}^{--}$generated by these cells, the $\mathrm{H}_{2} \mathrm{O}_{2}$ produced by dismutation has positive outcomes when the oxidative stimulus is moderate and physiological (zona hardening and oocyte maturation). However negative outcomes (impaired functionality, senescence, DNA damage and impaired chromosome segregation) are observed when ROS are produced in excess (Kala et al. 2017). Once again, lipid aldehydes such as, 4-HNE is a key mediator of pathological change. 
rates. The results achieved with this form of insemination are enhanced by lowering ambient oxygen tensions $(20-5 \%)$ or the inclusion of antioxidants in the culture medium such as reduced glutathione (Ashibe et al. 2019). Even though high levels of oxidative sperm DNA damage are tolerated by the oocyte in terms of fertilization and pronucleus formation (Twigg et al. 1998), it is in the subsequent development of the embryo that the impact of oxidative stress becomes manifest particularly in terms of mitotic arrest after ICSI (Burruel et al. 2013). This maybe because of the presence of high levels of unresolved DNA damage leading to the induction of apoptosis or the creation elevated mutational loads as a consequence of aberrant or defective DNA repair. In addition, since the spermatozoon's centromeres are responsible for orchestrating all cell division in the embryo, it is possible that oxidative damage to this subcellular structure in the male gamete results in the impairment of ordered mitosis in the offspring. We have recently found evidence for such an effect in annelid spermatozoa exposed to dibutyl phthalate. This toxicant created a state of oxidative stress in the spermatozoa resulting in the generation of 4-HNE which covalently bound to the sperm centriole, ultimately resulting in disrupted cytoskeletal protein organization during early embryonic cleavage (Lu et al. 2017). The extent to which such epigenetic mechanisms may underlie the impact of oxidative stress in the male germ line on the postfertilization developmental normality of embryos from other species is unknown.

\section{Conclusions}

Oxidative stress is clearly a major determinant of functionality in both the male and female germ lines. In the male germ line, there is clear evidence that a low level of ROS generation is beneficial for sperm function, achieving a range of functions from the cross linking of sperm chromatin to the enhancement of sperm capacitation. However, in a variety of situations (cryopreservation, toxicant exposure, age etc.) the generation of ROS becomes super-physiological and overpowers the limited antioxidant defences of these cells precipitating a state of oxidative stress that can impair both sperm production and function and ultimately impact the health trajectory of the offspring. Although we have made some progress in understanding the various sources of ROS in these cells, we are still awaiting a full explanation of the genetic, epigenetic and environmental factors responsible for the oxidative stress seen in subfertile males. In the female germ line, no positive role for ROS has been suggested; however, it is clear that oocytes are vulnerable to the damaging impact of these toxic metabolites if the exposure is intense and/or adequately prolonged. As in the male germ line, cryopreservation, toxicant exposure and ageing, whether in vitro or in vivo, are all factors in creating pathological levels of oxidative stress in the female germ line with potential impacts on both fertility and the normality of any resulting embryos. Given the susceptibility of reproduction to oxidative stress, antioxidants should be of fundamental significance in preserving the functional integrity of the male and female germ line. Despite the potential inherent in this field and certain islands of promising data, there is little science behind either the precise nature or the dose of antioxidants that have been used to address oxidative stress in vivo or in vitro. The lack of clinical trials wherein patients are selected for antioxidant therapy based on evidence that their infertility is due to oxidative stress is particularly distressing. Hopefully this deficit will be addressed in the not-too-distant future.

\section{Declaration of interest}

The author declares that he is an honorary advisor for CellOxess, a company specializing in the development of antioxidant formulations for the treatment of human infertility.

\section{Funding}

This research did not receive any specific grant from any funding agency in the public, commercial or not-for-profit sector.

\section{References}

Agarwal A, Sharma RK, Desai NR, Prabakaran S, Tavares A \& Sabanegh E 2009 Role of oxidative stress in pathogenesis of varicocele and infertility. Urology 73 461-469. (https://doi.org/10.1016/j.urology.2008.07.053)

Ahmadi E, Shirazi A, Shams-Esfandabadi N \& Nazari H 2019 Antioxidants and glycine can improve the developmental competence of vitrified/ warmed ovine immature oocytes. Reproduction in Domestic Animals = Zuchthygiene 54 595-603. (https://doi.org/10.1111/ rda.13402)

Aitken RJ 2018 Not every sperm is sacred; a perspective on male infertility. Molecular Human Reproduction 24 287-298. (https://doi.org/10.1093/ molehr/gay010)

Aitken RJ \& Baker MA 2013 Oxidative stress, spermatozoa and leukocytic infiltration: relationships forged by the opposing forces of microbial invasion and the search for perfection. Journal of Reproductive Immunology 100 11-19. (https://doi.org/10.1016/j.jri.2013.06.005)

Aitken RJ \& Curry BJ 2011 Redox regulation of human sperm function: from the physiological control of sperm capacitation to the etiology of infertility and DNA damage in the germ line. Antioxidants and Redox Signaling 14 367-381. (https://doi.org/10.1089/ars.2010.3186)

Aitken RJ \& Nixon B 2013 Sperm capacitation: a distant landscape glimpsed but unexplored. Molecular Human Reproduction 19 785-793. (https://doi.org/10.1093/molehr/gat067)

Aitken RJ, Buckingham D \& Harkiss D 1993 Use of a xanthine oxidase free radical generating system to investigate the cytotoxic effects of reactive oxygen species on human spermatozoa. Journal of Reproduction and Fertility 97 441-450. (https://doi.org/10.1530/jrf.0.0970441)

Aitken J, Krausz C \& Buckingham D 1994 Relationships between biochemical markers for residual sperm cytoplasm, reactive oxygen species generation, and the presence of leukocytes and precursor germ cells in human sperm suspensions. Molecular Reproduction and Development 39 268-279. (https://doi.org/10.1002/mrd.1080390304)

Aitken RJ, Fisher HM, Fulton N, Gomez E, Knox W, Lewis B \& Irvine S 1997 Reactive oxygen species generation by human spermatozoa is induced by exogenous NADPH and inhibited by the flavoprotein inhibitors 
diphenylene iodonium and quinacrine. Molecular Reproduction and Development 47 468-482. (https://doi.org/10.1002/(SICl)10982795(199708)47:4<468::AID-MRD14>3.0.CO;2-S)

Aitken RJ, Gordon E, Harkiss D, Twigg JP, Milne P, Jennings Z \& Irvine DS 1998a Relative impact of oxidative stress on the functional competence and genomic integrity of human spermatozoa. Biology of Reproduction 59 1037-1046. (https://doi.org/10.1095/biolreprod59.5.1037)

Aitken RJ, Harkiss D, Knox W, Paterson M \& Irvine DS 1998b A novel signal transduction cascade in capacitating human spermatozoa characterised by a redox-regulated, cAMP-mediated induction of tyrosine phosphorylation. Journal of Cell Science 111 645-656.

Aitken RJ, Ryan AL, Curry BJ \& Baker MA 2003 Multiple forms of redox activity in populations of human spermatozoa. Molecular Human Reproduction 9 645-661. (https://doi.org/10.1093/molehr/gag086)

Aitken RJ, Wingate JK, De Iuliis GN, Koppers AJ \& McLaughlin EA 2006 Cis-unsaturated fatty acids stimulate reactive oxygen species generation and lipid peroxidation in human spermatozoa. Journal of Clinical Endocrinology and Metabolism 91 4154-4163. (https://doi.org/10.1210/ jc.2006-1309)

Aitken RJ, Whiting S, De Iuliis GN, McClymont S, Mitchell LA \& Baker MA 2012 Electrophilic aldehydes generated by sperm metabolism activate mitochondrial reactive oxygen species generation and apoptosis by targeting succinate dehydrogenase. Journal of Biological Chemistry 287 33048-33060. (https://doi.org/10.1074/jbc.M112.366690)

Aitken JB, Naumovski N, Curry B, Grupen CG, Gibb Z\& Aitken RJ 2015a Characterization of an L-amino acid oxidase in equine spermatozoa. Biology of Reproduction 92 125. (https://doi.org/10.1095/ biolreprod.114.126052)

Aitken RJ, Baker MA \& Nixon B 2015b Are sperm capacitation and apoptosis the opposite ends of a continuum driven by oxidative stress? Asian Journal of Andrology 17 633-639. (https://doi.org/10.4103/1008682X.153850)

Alvarez JG, Touchstone JC, Blasco L \& Storey BT 1987 Spontaneous lipid peroxidation and production of hydrogen peroxide and superoxide in human spermatozoa. Superoxide dismutase as major enzyme protectant against oxygen toxicity. Journal of Andrology 8 338-348. (https://doi. org/10.1002/j.1939-4640.1987.tb00973.x)

An Q, Peng W, Cheng Y, Lu Z, Zhou C, Zhang Y \& Su J 2019 Melatonin supplementation during in vitro maturation of oocyte enhances subsequent development of bovine cloned embryos. Journal of Cell Physiology 234 17370-17381. (https://doi.org/10.1002/jcp.28357)

Arias-Álvarez M, García-García RM, López-Tello J, Rebollar PG, Gutiérrez-Adán A \& Lorenzo PL $2018 \alpha$-Tocopherol modifies the expression of genes related to oxidative stress and apoptosis during in vitro maturation and enhances the developmental competence of rabbit oocytes. Reproduction, Fertility, and Development 30 1728-1738. (https://doi.org/10.1071/RD17525)

Ashibe S, Miyamoto R, Kato Y \& Nagao Y 2019 Detrimental effects of oxidative stress in bovine oocytes during intracytoplasmic sperm injection (ICSI). Theriogenology 133 71-78. (https://doi.org/10.1016/j. theriogenology.2019.04.012)

Babior BM, Kipnes RS \& Curnutte JT 1973 Biological defense mechanisms. The production by leukocytes of superoxide, a potential bactericidal agent. Journal of Clinical Investigation 52 741-744. (https://doi. org/10.1172/JCI107236)

Baker MA, Krutskikh A, Curry BJ, McLaughlin EA \& Aitken RJ 2004 Identification of cytochrome P450-reductase as the enzyme responsible for NADPH-dependent lucigenin and tetrazolium salt reduction in rat epididymal sperm preparations. Biology of Reproduction 71 307-318. (https://doi.org/10.1095/biolreprod.104.027748)

Baker MA, Krutskikh A, Curry BJ, Hetherington L \& Aitken RJ 2005 Identification of cytochrome-b5 reductase as the enzyme responsible for NADH-dependent lucigenin chemiluminescence in human spermatozoa. Biology of Reproduction 73 334-342. (https://doi. org/10.1095/biolreprod.104.037960)

Barbonetti A, Castellini C, Di Giammarco N, Santilli G, Francavilla S \& Francavilla F 2016 In vitro exposure of human spermatozoa to bisphenol A induces pro-oxidative/apoptotic mitochondrial dysfunction. Reproductive Toxicology 66 61-67. (https://doi.org/10.1016/j.reprotox.2016.09.014)

Bisht S, Faiq M, Tolahunase M \& Dada R 2017 Oxidative stress and male infertility. Nature Reviews: Urology 14 470-485. (https://doi. org/10.1038/nrurol.2017.69)
Bize I, Santander G, Cabello P, Driscoll D \& Sharpe C 1991 Hydrogen peroxide is involved in hamster sperm capacitation in vitro. Biology of Reproduction 44 398-403. (https://doi.org/10.1095/biolreprod44.3.398)

Bromfield EG, Aitken RJ, McLaughlin EA \& Nixon B 2017 Proteolytic degradation of heat shock protein A2 occurs in response to oxidative stress in male germ cells of the mouse. Molecular Human Reproduction 23 91-105. (https://doi.org/10.1093/molehr/gaw074)

Bromfield EG, Walters JLH, Cafe SL, Bernstein IR, Stanger SJ, Anderson AL, Aitken RJ, McLaughlin EA, Dun MD, Gadella BM et al. 2019 Differential cell death decisions in the testis: evidence for an exclusive window of ferroptosis in round spermatids. Molecular Human Reproduction 25 241-256. (https://doi.org/10.1093/molehr/gaz015)

Brouwers JF, Boerke A, Silva PF, Garcia-Gil N, van Gestel RA, Helms JB, van de Lest $\mathbf{C H}$ \& Gadella BM 2011 Mass spectrometric detection of cholesterol oxidation in bovine sperm. Biology of Reproduction $\mathbf{8 5}$ 128-136. (https://doi.org/10.1095/biolreprod.111.091207)

Burruel V, Klooster KL, Chitwood J, Ross PJ \& Meyers SA 2013 Oxidative damage to rhesus macaque spermatozoa results in mitotic arrest and transcript abundance changes in early embryos. Biology of Reproduction 89 72. (https://doi.org/10.1095/biolreprod.113.110981)

Burton GJ \& Jauniaux E 2011 Oxidative stress. Best Practice and Research: Clinical Obstetrics and Gynaecology 25 287-299. (https://doi. org/10.1016/j.bpobgyn.2010.10.016)

Calvert SJ, Reynolds S, Paley MN, Walters SJ \& Pacey AA 2019 Probing human sperm metabolism using 13C-magnetic resonance spectroscopy. Molecular Human Reproduction 25 30-41. (https://doi.org/10.1093/ molehr/gay046)

Cassina A, Silveira P, Cantu L, Montes JM, Radi R \& Sapiro R 2015 Defective human sperm cells are associated with mitochondrial dysfunction and oxidant production. Biology of Reproduction 93 119. (https://doi. org/10.1095/biolreprod.115.130989)

Castellano F \& Molinier-Frenkel V 2017 An overview of I-amino acid oxidase functions from bacteria to mammals: focus on the immunoregulatory phenylalanine oxidase IL4I1. Molecules 22 E2151. (https://doi.org/10.3390/molecules22122151)

Cavallari FC, Leal CLV, Zvi R \& Hansen PJ 2019 Effects of melatonin on production of reactive oxygen species and developmental competence of bovine oocytes exposed to heat shock and oxidative stress during in vitro maturation. Zygote 27 180-186. (https://doi.org/10.1017/ S0967199419000236)

Chao HT, Lee SY, Lee HM, Liao TL, Wei YH \& Kao SH 2005 Repeated ovarian stimulations induce oxidative damage and mitochondrial DNA mutations in mouse ovaries. Annals of the New York Academy of Sciences 1042 148-156. (https://doi.org/10.1196/annals.1338.016)

Das S, Chattopadhyay R, Ghosh S, Ghosh S, Goswami SK, Chakravarty BN \& Chaudhury K 2006 Reactive oxygen species level in follicular fluid - embryo quality marker in IVF? Human Reproduction 21 2403-2407. (https://doi.org/10.1093/humrep/del156)

de Lamirande E \& Gagnon C 1992 Reactive oxygen species and human spermatozoa. II. Depletion of adenosine triphosphate plays an important role in the inhibition of sperm motility. Journal of Andrology 13 379-386.

de Lamirande E \& Gagnon C 1993 Human sperm hyperactivation and capacitation as parts of an oxidative process. Free Radical Biology and Medicine 14 157-166. (https://doi.org/10.1016/0891-5849(93)90006-g) de Lamirande E \& Lamothe G 2010 Levels of semenogelin in human spermatozoa decrease during capacitation: involvement of reactive oxygen species and zinc. Human Reproduction 25 1619-1630. (https:// doi.org/10.1093/humrep/deq110)

de Lamirande E, Lamothe G \& Villemure M 2009 Control of superoxide and nitric oxide formation during human sperm capacitation. Free Radical Biology and Medicine 46 1420-1427. (https://doi.org/10.1016/j. freeradbiomed.2009.02.022)

Domínguez-Perles R, Gil-Izquierdo A, Ferreres F \& Medina S 2019 Update on oxidative stress and inflammation in pregnant women, unborn children (nasciturus), and newborns - nutritional and dietary effects. Free Radical Biology and Medicine 142 38-51. (https://doi.org/10.1016/j. freeradbiomed.2019.03.013)

Donà G, Fiore C, Andrisani A, Ambrosini G, Brunati A, Ragazzi E, Armanini D, Bordin L \& Clari G 2011 Evaluation of correct endogenous reactive oxygen species content for human sperm capacitation and involvement of the NADPH oxidase system. Human Reproduction 26 3264-3273. (https://doi.org/10.1093/humrep/der321) 
Ecroyd HW, Jones RC \& Aitken RJ 2003 Endogenous redox activity in mouse spermatozoa and its role in regulating the tyrosine phosphorylation events associated with sperm capacitation. Biology of Reproduction 69 347-354. (https://doi.org/10.1095/biolreprod.102.012716)

Eini F, Bidadkosh A, Nazarian H, Piryaei A, Ghaffari Novin M \& Joharchi K 2019 Thymoquinone reduces intracytoplasmic oxidative stress and improves epigenetic modification in polycystic ovary syndrome mice oocytes, during in-vitro maturation. Molecular Reproduction and Development 86 1053-1066. (https://doi.org/10.1002/mrd.23222)

Elhassan YM, Wu G, Leanez AC, Tasca RJ, Watson AJ \& Westhusin ME 2001 Amino acid concentrations in fluids from the bovine oviduct and uterus and in KSOM-based culture media. Theriogenology $\mathbf{5 5}$ 1907-1918. (https://doi.org/10.1016/s0093-691x(01)00532-5)

Fischer KA, Van Leyen K, Lovercamp KW, Manandhar G, Sutovsky M, Feng D, Safranski T \& Sutovsky P 2005 15-Lipoxygenase is a component of the mammalian sperm cytoplasmic droplet. Reproduction 130 213-222. (https://doi.org/10.1530/rep.1.00646)

Gad A, Abu Hamed S, Khalifa M, Amin A, El-Sayed A, Swiefy SA \& ElAssal S 2018 Retinoic acid improves maturation rate and upregulates the expression of antioxidant-related genes in in vitro matured buffalo (Bubalus bubalis) oocytes. International Journal of Veterinary Science and Medicine 6 279-285. (https://doi.org/10.1016/j.ijvsm.2018.09.003)

Ghanbari H, Keshtgar S, Zare HR \& Gharesi-Fard B 2019 Inhibition of CatSper and Hv1 channels and NOX5 enzyme affect progesteroneinduced increase of intracellular calcium concentration and ROS Generation in human sperm. Iranian Journal of Medical Sciences $\mathbf{4 4}$ 127-134.

Gharagozloo P, Gutiérrez-Adán A, Champroux A, Noblanc A, Kocer A, Calle A, Pérez-Cerezales S, Pericuesta E, Polhemus A, Moazamian A et al. 2016 A novel antioxidant formulation designed to treat male infertility associated with oxidative stress: promising preclinical evidence from animal models. Human Reproduction 31 252-262. (https://doi. org/10.1093/humrep/dev302

Ghorbanmehr N, Salehnia M \& Amooshahi M 2018 The effects of sodium selenite on mitochondrial DNA copy number and reactive oxygen species levels of in vitro matured mouse oocytes. Cell Journal 20 396-402. (https://doi.org/10.22074/cellj.2018.5430)

Gomez E, Buckingham DW, Brindle J, Lanzafame F, Irvine DS \& Aitken RJ 1996 Development of an image analysis system to monitor the retention of residual cytoplasm by human spermatozoa: correlation with biochemical markers of the cytoplasmic space, oxidative stress, and sperm function. Journal of Andrology 17 276-287.

Goud AP, Goud PT, Diamond MP, Gonik B \& Abu-Soud HM 2008 Reactive oxygen species and oocyte aging: role of superoxide, hydrogen peroxide, and hypochlorous acid. Free Radical Biology and Medicine 44 1295-1304. (https://doi.org/10.1016/j.freeradbiomed.2007.11.014)

Griffin RA, Baker M, Aitken RJ, Swegen A \& Gibb Z 2019 What makes a fertile sperm? Unique molecular attributes of stallion fertility. Reproduction 158 R125-R137. (https://doi.org/10.1530/REP-19-0060)

Hawkins DJ \& Brash AR 1987 Eggs of the sea urchin, Strongylocentrotus purpuratus, contain a prominent $(11 \mathrm{R})$ and $(12 \mathrm{R})$ lipoxygenase activity. Journal of Biological Chemistry 262 7629-7634.

He YT, Wang W, Shen W, Sun QY \& Yin S 2019 Melatonin protects against fenoxaprop-ethyl exposure-induced meiotic defects in mouse oocytes. Toxicology 425 152241. (https://doi.org/10.1016/j.tox.2019.152241)

Herrero MB, de Lamirande E \& Gagnon C 1999 Nitric oxide regulates human sperm capacitation and protein-tyrosine phosphorylation in vitro. Biology of Reproduction 61 575-581. (https://doi.org/10.1095/ biolreprod61.3.575)

Herrero MB, de Lamirande E \& Gagnon C 2001 Tyrosine nitration in human spermatozoa: a physiological function of peroxynitrite, the reaction product of nitric oxide and superoxide. Molecular Human Reproduction 7 913-921. (https://doi.org/10.1093/molehr/7.10.913)

Heydarnejad A, Ostadhosseini S, Varnosfaderani SR, Jafarpour F, Moghimi A \& Nasr-Esfahani MH 2019 Supplementation of maturation medium with CoQ10 enhances developmental competence of ovine oocytes through improvement of mitochondrial function. Molecular Reproduction and Development 86 812-824. (https://doi.org/10.1002/ mrd.23159)

Hoodbhoy T \& Talbot P 1994 Mammalian cortical granules: contents, fate, and function. Molecular Reproduction and Development 39 439-448. (https://doi.org/10.1002/mrd.1080390413)
Houston B, Curry B \& Aitken RJ 2015 Human spermatozoa possess an IL4I1 I-amino acid oxidase with a potential role in sperm function. Reproduction 149 587-596. (https://doi.org/10.1530/REP-14-0621)

Houston BJ, Nixon B, King BV, De luliis GN \& Aitken RJ 2016 The effects of radiofrequency electromagnetic radiation on sperm function. Reproduction 152 R263-R276. (https://doi.org/10.1530/ REP-16-0126)

Houston BJ, Nixon B, King BV, Aitken RJ \& De luliis GN 2018 Probing the origins of $1,800 \mathrm{MHz}$ radio frequency electromagnetic radiation induced damage in mouse immortalized germ cells and spermatozoa in vitro. Frontiers in Public Health 6 270. (https://doi.org/10.3389/ fpubh.2018.00270)

Hussein MR, Abu-Dief EE, Abou El-Ghait AT, Adly MA \& Abdelraheem MH 2006 Morphological evaluation of the radioprotective effects of melatonin against X-ray-induced early and acute testis damage in albino rats: an animal model. International Journal of Experimental Pathology 87 237-250. (https://doi.org/10.1111/j.1365-2613.2006.00480.x)

Ishii T, Matsuki S, luchi Y, Okada F, Toyosaki S, Tomita Y, Ikeda Y \& Fujii J 2005 Accelerated impairment of spermatogenic cells in SOD1-knockout mice under heat stress. Free Radical Research 39 697-705. (https://doi. org/10.1080/10715760500130517)

Jeelani R, Chatzicharalampous C, Kohan-Ghadr HR, Awonuga A, Joshi N, Morris RT \& Abu-Soud HM 2018 Acrolein, a commonly found environmental toxin, causes oocyte mitochondrial dysfunction and negatively affects embryo development. Free Radical Research $\mathbf{5 2}$ 929-938. (https://doi.org/10.1080/10715762.2018.1487559)

Kala M, Shaikh MV \& Nivsarkar M 2017 Equilibrium between anti-oxidants and reactive oxygen species: a requisite for oocyte development and maturation. Reproductive Medicine and Biology 16 28-35. (https://doi. org/10.1002/rmb2.12013)

Kalezic A, Macanovic B, Garalejic E, Korac A, Otasevic V \& Korac B 2018 Level of $\mathrm{NO} /$ nitrite and 3-nitrotyrosine in seminal plasma of infertile men: correlation with sperm number, motility and morphology. Chemico-Biological Interactions 291 264-270. (https://doi.org/10.1016/j. cbi.2018.07.002)

Kermack AJ, Finn-Sell S, Cheong YC, Brook N, Eckert JJ, Macklon NS \& Houghton FD 2015 Amino acid composition of human uterine fluid: association with age, lifestyle and gynaecological pathology. Human Reproduction 30 917-924. (https://doi.org/10.1093/humrep/dev008)

Khairallah RJ, O'Shea KM, Brown BH, Khanna N, Des Rosiers C \& Stanley WC 2010 Treatment with docosahexaenoic acid, but not eicosapentaenoic acid, delays $\mathrm{Ca} 2+$-induced mitochondria permeability transition in normal and hypertrophied myocardium. Journal of Pharmacology and Experimental Therapeutics 335 155-162. (https://doi. org/10.1124/jpet.110.170605)

Kim WJ, Lee SE, Park YG, Jeong SG, Kim EY \& Park SP 2019 Antioxidant hesperetin improves the quality of porcine oocytes during aging in vitro. Molecular Reproduction and Development 86 32-41. (https://doi. org/10.1002/mrd.23079)

Koppers AJ, De Iuliis GN, Finnie JM, McLaughlin EA \& Aitken RJ 2008 Significance of mitochondrial reactive oxygen species in the generation of oxidative stress in spermatozoa. Journal of Clinical Endocrinology and Metabolism 93 3199-3207. (https://doi.org/10.1210/jc.2007-2616)

Koppers AJ, Mitchell LA, Wang P, Lin M \& Aitken RJ 2011 Phosphoinositide 3-kinase signalling pathway involvement in a truncated apoptotic cascade associated with motility loss and oxidative DNA damage in human spermatozoa. Biochemical Journal 436 687-698. (https://doi. org/10.1042/BJ20110114)

Koppers AJ, Garg ML \& Aitken RJ 2010 Stimulation of mitochondrial reactive oxygen species production by unesterified, unsaturated fatty acids in defective human spermatozoa. Free Radical Biology and Medicine $\mathbf{4 8}$ 112-119. (https://doi.org/10.1016/j.freeradbiomed.2009.10.033)

Kovacic P \& Jacintho JD 2001 Reproductive toxins: pervasive theme of oxidative stress and electron transfer. Current Medicinal Chemistry 8 863-892. (https://doi.org/10.2174/0929867013372878)

Kumar Roy V, Marak TR \& Gurusubramanian G 2016 Alleviating effect of Mallotus roxburghianus in heat-induced testicular dysfunction in Wistar rats. Pharmaceutical Biology 54 905-918. (https://doi.org/10.3109/1388 0209.2015.1091480)

Lapointe S \& Sirard MA 1998 Catalase and oviductal fluid reverse the decreased motility of bovine sperm in culture medium containing specific amino acids. Journal of Andrology 19 31-36. 
Lewis B \& Aitken RJ 2001 A redox-regulated tyrosine phosphorylation cascade in rat spermatozoa. Journal of Andrology 22 611-622.

Li Q \& Zhao Z 2019 Influence of N-acetyl-L-cysteine against bisphenol A on the maturation of mouse oocytes and embryo development: in vitro study. BMC Pharmacology and Toxicology 20 43. (https://doi. org/10.1186/s40360-019-0323-9)

Liang QX, Lin YH, Zhang CH, Sun HM, Zhou L, Schatten H, Sun QY \& Qian WP 2018 Resveratrol increases resistance of mouse oocytes to postovulatory aging in vivo. Aging 10 1586-1596. (https://doi. org/10.18632/aging.101494)

Liu M, Yin Y, Ye X, Zeng M, Zhao Q, Keefe DL \& Liu L 2013 Resveratrol protects against age-associated infertility in mice. Human Reproduction 28 707-717. (https://doi.org/10.1093/humrep/des437)

Lord T \& Aitken RJ 2013 Oxidative stress and ageing of the post-ovulatory oocyte. Reproduction 146 R217-R227. (https://doi.org/10.1530/REP-130111)

Lord T, Martin JH \& Aitken RJ 2015 Accumulation of electrophilic aldehydes during postovulatory aging of mouse oocytes causes reduced fertility, oxidative stress, and apoptosis. Biology of Reproduction 9233. (https://doi.org/10.1095/biolreprod.114.122820)

Lu Y, Lin M \& Aitken RJ 2017 Exposure of spermatozoa to dibutyl phthalate induces abnormal embryonic development in a marine invertebrate Galeolaria caespitosa (Polychaeta: Serpulidae). Aquatic Toxicology 191 189-200. (https://doi.org/10.1016/j.aquatox.2017.08.008)

Lu J, Wang Z, Cao J, Chen Y \& Dong Y 2018 A novel and compact review on the role of oxidative stress in female reproduction. Reproductive Biology and Endocrinology 16 80. (https://doi.org/10.1186/s12958-0180391-5)

MacLeod J 1943 The role of oxygen in the metabolism and motility of human spermatozoa. American Journal of Physiology: Legacy Content 138 512-518. (https://doi.org/10.1152/ajplegacy.1943.138.3.512)

Maiti K, Sultana Z, Aitken RJ, Morris J, Park F, Andrew B, Riley SC \& Smith R 2017 Evidence that fetal death is associated with placental aging. American Journal of Obstetrics and Gynecology 217 441.e1-441. e14. (https://doi.org/10.1016/j.ajog.2017.06.015)

Martin JH, Nixon B, Lord T, Bromfield EG \& Aitken RJ 2016 Identification of a key role for permeability glycoprotein in enhancing the cellular defence mechanisms of fertilized oocytes. Developmental Biology $\mathbf{4 1 7}$ 63-76. (https://doi.org/10.1016/j.ydbio.2016.06.035)

Maru Y, Nishino T \& Kakinuma K 2005 Expression of Nox genes in rat organs, mouse oocytes, and sea urchin eggs. DNA Sequence 16 83-88. (https://doi.org/10.1080/10425170500069734)

Mihalas BP, Redgrove KA, McLaughlin EA \& Nixon B 2017 Molecular mechanisms responsible for increased vulnerability of the ageing oocyte to oxidative damage. Oxidative Medicine and Cellular Longevity 2017 4015874. (https://doi.org/10.1155/2017/4015874)

Moon SH, Liu X, Cedars AM, Yang K, Kiebish MA, Joseph SM, Kelley J, Jenkins CM \& Gross RW 2018 Heart failure-induced activation of phospholipase iPLA2 $\gamma$ generates hydroxyeicosatetraenoic acids opening the mitochondrial permeability transition pore. Journal of Biological Chemistry 293 115-129. (https://doi.org/10.1074/jbc.RA117.000405)

Musset B, Clark RA, DeCoursey TE, Petheo GL, Geiszt M, Chen Y, Cornell JE, Eddy CA, Brzyski RG \& El Jamali A 2012 NOX5 in human spermatozoa: expression, function, and regulation. Journal of Biological Chemistry 287 9376-9388. (https://doi.org/10.1074/jbc.M111.314955)

Nowicka-Bauer K, Lepczynski A, Ozgo M, Kamieniczna M, Fraczek M, Stanski L, Olszewska M, Malcher A, Skrzypczak W \& Kurpisz MK 2018 Sperm mitochondrial dysfunction and oxidative stress as possible reasons for isolated asthenozoospermia. Journal of Physiology and Pharmacology 69 3. (https://doi.org/10.26402/jpp.2018.3.05)

Ogilvy-Stuart AL \& Shalet SM 1993 Effect of radiation on the human reproductive system. Environmental Health Perspectives 101 (Supplement 2) 109-116. (https://doi.org/10.1289/ehp.93101s2109)

Ortiz-Rodriguez JM, Ortega-Ferrusola C, Gil MC, Martín-Cano FE, Gaitskell-Phillips G, Rodríguez-Martínez H, Hinrichs K, ÁlvarezBarrientos A, Román Á \& Peña FJ 2019 Transcriptome analysis reveals that fertilization with cryopreserved sperm downregulates genes relevant for early embryo development in the horse. PLOS ONE 14 e0213420. (https://doi.org/10.1371/journal.pone.0213420)

Park SJ, Kim JH, Lee DG, Kim JM \& Lee DS 2018 Peroxiredoxin 2 deficiency accelerates age-related ovarian failure through the reactive oxygen species-mediated JNK pathway in mice. Free Radical
Biology and Medicine 123 96-106. (https://doi.org/10.1016/j. freeradbiomed.2018.05.059)

Pasquariello R, Ermisch AF, Silva E, McCormick S, Logsdon D, Barfield JP, Schoolcraft WB \& Krisher RL 2019 Alterations in oocyte mitochondrial number and function are related to spindle defects and occur with maternal aging in mice and humans. Biology of Reproduction 100 971-981. (https://doi.org/10.1093/biolre/ioy248)

Peng TI \& Jou MJ 2010 Oxidative stress caused by mitochondrial calcium overload. Annals of the New York Academy of Sciences 1201 183-188. (https://doi.org/10.1111/j.1749-6632.2010.05634.x)

Perkins AT, Greig MM, Sontakke AA, Peloquin AS, McPeek MA \& Bickel SE 2019 Increased levels of superoxide dismutase suppress meiotic segregation errors in aging oocytes. Chromosoma 128 215-222. (https:// doi.org/10.1007/s00412-019-00702-y)

Rajpert-De Meyts E, McGlynn KA, Okamoto K, Jewett MAS \& Bokemeyer C 2016 Testicular germ cell tumours. Lancet 387 1762-1774. (https://doi. org/10.1016/S0140-6736(15)00991-5)

Rivlin J, Mendel J, Rubinstein S, Etkovitz N \& Breitbart H 2004 Role of hydrogen peroxide in sperm capacitation and acrosome reaction. Biology of Reproduction 70 518-522. (https://doi.org/10.1095/ biolreprod.103.020487)

Samarasinghe SVAC, Krishnan K, Naidu R, Megharaj M, Miller K, Fraser B \& Aitken RJ 2018 Parabens generate reactive oxygen species in human spermatozoa. Andrology 6 532-541. (https://doi.org/10.1111/ andr.12499)

Sengoku K, Tamate K, Yoshida T, Takaoka Y, Miyamoto T \& Ishikawa M 1998 Effects of low concentrations of nitric oxide on the zona pellucida binding ability of human spermatozoa. Fertility and Sterility 69 522-527. (https://doi.org/10.1016/s0015-0282(97)00537-2)

Shannon P \& Curson B 1982 Kinetics of the aromatic L-amino acid oxidase from dead bovine spermatozoa and the effect of catalase on fertility of diluted bovine semen stored at 5 degrees $\mathrm{C}$ and ambient temperatures. Journal of Reproduction and Fertility 64 463-467. (https:// doi.org/10.1530/jrf.0.0640463)

Snell GD \& Aebersold PC 1937 The production of sterility in male mice by irradiation with neutrons. PNAS 23 374-378. (https://doi.org/10.1073/ pnas.23.7.374)

Storey BT 2008 Mammalian sperm metabolism: oxygen and sugar, friend and foe. International Journal of Developmental Biology 52 427-437. (https://doi.org/10.1387/ijdb.072522bs)

Swann K \& Lai FA 2016 Egg activation at fertilization by a soluble sperm protein. Physiological Reviews 96 127-149. (https://doi.org/10.1152/ physrev.00012.2015)

Tarín JJ, Vendrell FJ, Ten J \& Cano A 1998 Antioxidant therapy counteracts the disturbing effects of diamide and maternal ageing on meiotic division and chromosomal segregation in mouse oocytes. Molecular Human Reproduction 4 281-288. (https://doi.org/10.1093/molehr/4.3.281)

Thomson LK, Fleming SD, Aitken RJ, De Iuliis GN, Zieschang JA \& Clark AM 2009 Cryopreservation-induced human sperm DNA damage is predominantly mediated by oxidative stress rather than apoptosis. Human Reproduction 24 2061-2070. (https://doi.org/10.1093/humrep/dep214)

Tosic J \& Walton A 1946 Formation of hydrogen peroxide by spermatozoa and its inhibitory effect on respiration. Nature 158 485. (https://doi. org/10.1038/158485a0)

Tosic J \& Walton A 1950 Metabolism of spermatozoa. The formation and elimination of hydrogen peroxide by spermatozoa and effects on motility and survival. Biochemical Journal 47 199-212. (https://doi.org/10.1042/ bj0470199)

Trapphoff T, Heiligentag M, Simon J, Staubach N, Seidel T, Otte K, Fröhlich T, Arnold GJ \& Eichenlaub-Ritter U 2016 Improved cryotolerance and developmental potential of in vitro and in vivo matured mouse oocytes by supplementing with a glutathione donor prior to vitrification. Molecular Human Reproduction 22 867-881. (https://doi.org/10.1093/molehr/gaw059)

Twigg JP, Irvine DS \& Aitken RJ 1998 Oxidative damage to DNA in human spermatozoa does not preclude pronucleus formation at intracytoplasmic sperm injection. Human Reproduction 13 1864-1871. (https://doi. org/10.1093/humrep/13.7.1864)

Upreti GC, Jensen K, Munday R, Duganzich DM, Vishwanath R \& Smith JF 1998 Studies on aromatic amino acid oxidase activity in ram spermatozoa: role of pyruvate as an antioxidant. Animal Reproduction Science 51 275-287. (https://doi.org/10.1016/s0378-4320(98)00082-7) 
Vaos G \& Zavras N 2017 Antioxidants in experimental ischemiareperfusion injury of the testis: where are we heading towards? World Journal of Methodology 7 37-45. (https://doi.org/10.5662/wjm.v7.i2.37)

Vatannejad A, Tavilani H, Sadeghi MR, Karimi M, Lakpour N, Amanpour S, Shabani Nashtaei M \& Doosti M 2019 Evaluation of the NOX5 protein expression and oxidative stress in sperm from asthenozoospermic men compared to normozoospermic men. Journal of Endocrinological Investigation 42 1181-1189. (https://doi.org/10.1007/s40618-01901035-4)

Vignini A, Nanetti L, Buldreghini E, Moroni C, Ricciardo-Lamonica G, Mantero F, Boscaro M, Mazzanti L \& Balercia G 2006 The production of peroxynitrite by human spermatozoa may affect sperm motility through the formation of protein nitrotyrosine. Fertility and Sterility 85 947-953. (https://doi.org/10.1016/j.fertnstert.2005.09.027)

Walters JLH, De Iuliis GN, Dun MD, Aitken RJ, McLaughlin EA, Nixon B \& Bromfield EG 2018 Pharmacological inhibition of arachidonate 15-lipoxygenase protects human spermatozoa against oxidative stress. Biology of Reproduction 98 784-794. (https://doi.org/10.1093/biolre/ ioy058)

Wang X, Sharma RK, Gupta A, George V, Thomas AJ, Falcone T \& Agarwal A 2003 Alterations in mitochondria membrane potential and oxidative stress in infertile men: a prospective observational study. Fertility and Sterility 80 (Supplement 2) 844-850. (https://doi.org/10.1016/s00150282(03)00983-x)

Wang Y, Zhang M, Chen ZJ \& Du Y 2018 Resveratrol promotes the embryonic development of vitrified mouse oocytes after in vitro fertilization. In Vitro Cellular and Developmental Biology: Animal 54 430-438. (https://doi.org/10.1007/s11626-018-0262-6)

White DR \& Aitken RJ 1989 Relationship between calcium, cyclic AMP, ATP, and intracellular $\mathrm{pH}$ and the capacity of hamster spermatozoa to express hyperactivated motility. Gamete Research 22 163-177. (https:// doi.org/10.1002/mrd.1120220205)

Wu M, Ma L, Xue L, Ye W, Lu Z, Li X, Jin Y, Qin X, Chen D, Tang W et al. 2019 Resveratrol alleviates chemotherapy-induced oogonial stem cell apoptosis and ovarian aging in mice. Aging 11 1030-1044. (https://doi. org/10.18632/aging.101808)
Xiao P, Nie J, Wang X, Lu K, Lu S \& Liang X 2019 Melatonin alleviates the deterioration of oocytes from mice subjected to repeated superovulation. Journal of Cellular Physiology 234 13413-13422. (https://doi.org/10.1002/ jcp.28018)

Yu L, Yang X, Ma B, Ying H, Shang X, He B \& Zhang Q 2019 Abnormal arachidonic acid metabolic network may reduce sperm motility via P38 MAPK. Open Biology 9 180091. (https://doi.org/10.1098/rsob.180091)

Zhang M, Jiang M, Bi Y, Zhu H, Zhou Z \& Sha J 2012 Autophagy and apoptosis act as partners to induce germ cell death after heat stress in mice. PLOS ONE 7 e41412. (https://doi.org/10.1371/journal.pone.0041412)

Zhang WD, Zhang Z, Jia LT, Zhang LL, Fu T, Li YS, Wang P, Sun L, Shi Y \& Zhang HZ 2014 Oxygen free radicals and mitochondrial signaling in oligospermia and asthenospermia. Molecular Medicine Reports $\mathbf{1 0}$ 1875-1880. (https://doi.org/10.3892/mmr.2014.2428)

Zhang Y, Guo J, Nie XW, Li ZY, Wang YM, Liang S \& Li S 2019 Rosmarinic acid treatment during porcine oocyte maturation attenuates oxidative stress and improves subsequent embryo development in vitro. Peer/ 7 e6930. (https://doi.org/10.7717/peerj.6930)

Zhong H \& Yin H 2015 Role of lipid peroxidation derived 4-hydroxynonenal (4-HNE) in cancer: focusing on mitochondria. Redox Biology 4 193-199. (https://doi.org/10.1016/j.redox.2014.12.011)

Zini A, De Lamirande E \& Gagnon C 1995 Low levels of nitric oxide promote human sperm capacitation in vitro. Journal of Andrology $\mathbf{1 6}$ 424-431.

Zorov DB, Juhaszova M \& Sollott SJ 2014 Mitochondrial reactive oxygen species (ROS) and ROS-induced ROS release. Physiological Reviews 94 909-950. (https://doi.org/10.1152/physrev.00026.2013)

Received 22 September 2019

First decision 21 November 2019

Revised manuscript received 12 December 2019

Accepted 17 December 2019 